\title{
The Multidimensional Nature of Product Perceptions within Asia
}

\author{
Giana M. Eckhardt ${ }^{1} \cdot$ Luming Wang $^{2}$ \\ Published online: 7 April 2015 \\ (C) Springer Science+Business Media New York 2015
}

\begin{abstract}
This paper seeks to understand how Asian consumers perceive Asian products, a topic that has received surprisingly little academic scrutiny to date. We demonstrate that there are systematic differences in perception effects across diverse product categories. These systematic differences are multidimensional and are interpretable in terms of country image as technology and fashion expertise. The authors demonstrate empirically that country of origin effects drive product perception in the region and that country of origin is a multidimensional construct that transcends product categories and regions. We do this using a novel methodological approach that analyzes data on product evaluations and on county perceptions simultaneously using a probabilistic spatial model. Understanding perceptions in multidimensional terms imply that developing countries should not simply imitate the strongest economy in a region, but should seek strong differentiated competitive positions. It also implies that this type of methodology is needed to flesh out the nuances of multidimensionality after accounting for other systematic product perception effects, such as consumer ethnocentrism, on behavior.
\end{abstract}

Keywords Branding $\cdot$ Asia $\cdot$ Market structure analysis · Bayesian analysis

This research project was carried out in conjunction with the McKinsey Consulting Asia-Pacific Marketing Practice.

Electronic supplementary material The online version of this article (doi:10.1007/s40547-015-0046-z) contains supplementary material, which is available to authorized users.

Giana M. Eckhardt

giana.eckhardt@rhul.ac.uk

Luming Wang

luming.wang@umanitoba.ca

1 School of Management, Royal Holloway University of London, Egham, Surrey TW20 0EX, UK

2 Asper School of Business, University of Manitoba, 676 Drake Center, 181 Freedman Crescent, Winnipeg, Manitoba R3T 5V4, Canada
Asia is a complex region to understand from a marketing perspective, due to its heterogeneity [8]. Many companies are increasingly turning to Asia to fuel their growth. This region represents a lucrative opportunity, not only for Western companies but also for Asian companies themselves. Yet, there is a mix of developed and developing countries, and, with the exception of Japan and South Korea, a distrust of Asian products, due to past histories of uneven product quality, even by their own citizens of those countries. Thus, Asian companies have increased hurdles to overcome as they struggle to gain traction in the marketplace.

To unravel some of these complexities, we can look toward understanding how Asian consumers perceive Asian products, a topic that has received surprisingly little academic scrutiny to date. This paper investigates the nature of product perceptions across a broad range of countries and product categories within Asia. The authors demonstrate empirically that country of origin effects drive product perception in the region and that country of origin is a multidimensional construct that transcends product categories and countries. The two dimensions which account for our effects are technology and fashion expertise. The authors find that no country is best on both dimensions, and hence, no country is the preferred country of origin for all types of products. This implies that developing countries should not simply imitate the strongest economy in a region but should seek strong differentiated competitive positions. Additionally, we could not have discovered the multidimensionality without our novel methodology that reveals the multiple dimensions through simultaneously modeling product evaluations and county perceptions after other systematic product perception effects, such as consumer ethnocentrism, on behavior have been accounted for. Thus, future country of origin research should treat and measure the construct as such.

\section{The Nature of Product Perceptions}

Scholars tend to examine how products are perceived in the context of single product categories (e.g., food in [28]) or two 
similar product categories (e.g., televisions and computers in [1]). Such microlevel studies are certainly invaluable; product managers require a detailed understanding of their specific product category, and insights derived from one category contribute to our understanding of overall perception effects. However, there is also a need for a broader investigation of perception effects that transcends product category. Do consumers have images of countries of origin that apply across widely differing product categories? Are the effects of these images multidimensional and, if so, are the dimensions comprehensible and meaningfully related to the product categories? Answers to these more macrolevel questions are not easily obtained by studying product categories separately.

Recent research has sought such macrolevel explanations by analyzing how consumers perceive countries of origin separately from the effects of these perceptions on consumer behavior [34]. Data on country perceptions are analyzed to yield interpretable representations of country images; a subsequent analysis then checks to see whether and how these images are related to county of origin (COO) effects on product evaluations. Focusing separately on country perceptions has resulted in a broader understanding of country image that goes beyond explanation of $\mathrm{COO}$ effects [34] while allowing for rigorous development and assessment of country image scales and constructs [38].

However, analyzing country perceptions in isolation has risks. The dimensions of country image are determined solely by agreement among the items used to measure country perceptions with no consideration of their relationship to consumer behavior. The risks are twofold. First, dimensions of country image so derived may be weakly related to $\mathrm{COO}$ effects on products $[35,36]$. This may explain why some developers of multidimensional country image constructs relate only the single unidimensional construct underlying these dimensions to behavior [24,27]. Second, assessing whether and how predetermined dimensions of country image are related to behavior leaves other systematic perception effects on behavior undetected and unaccounted for.

\section{Our Contribution}

This paper makes theoretical and methodological contributions. It complements recent research on perceptions by presenting a probabilistic spatial model that analyzes data on product evaluations and on county perceptions simultaneously, which provides a more flexible approach to dealing with more complex market structures and perceptual dimensions. Four nationalities of consumers evaluate ten countries of origin for each of ten product categories. They also rate these ten countries of origin on each of ten country attributes. The countries and product categories differ widely so as to provide macrolevel insights into product perception effects.
The result is a characterization of countries in one or more dimensions that explains country perceptions and $\mathrm{COO}$ effects on product evaluations. The countries will vary most on dimensions that account for both perceptions and evaluations, revealing pictorially why countries are preferred for some product categories more than others. Yet, systematic $\mathrm{COO}$ effects on product evaluations unassociated with country perceptions are also detectable, as are systematic differences in country perceptions unrelated to product evaluations. Such effects are revealed by additional dimensions in which countries vary with products but not country attributes and other dimensions in which countries vary with country attributes but not products. Thus, the model can be used to guide development of robust scales of country image that are predictive of $\mathrm{COO}$ effects on product evaluations. In sum, we reveal that country of origin is a multidimensional construct that transcends product categories and regions, and we demonstrate this empirically.

\section{Conceptual Development}

$\mathrm{COO}$ research has relied on standard multivariate statistical methods [34]. These methods (principal components analysis, factor analysis, multidimensional scaling or unfolding, canonical correlation) are designed for two-way data-that is, data with only two subscripts [6]. Multigroup confirmatory factor analysis allows factor loadings to vary according to a third subscript indicating group membership of respondents, but such group differences are not explained. Studies seeking to explain $\mathrm{COO}$ effects on product evaluation and choice in terms of country perceptions entail analysis of data that varies by consumer, product, country, and country attributes. Consumers of different nationalities evaluate different products coming from different countries (three-way data) and also different countries on different attributes (three-way again). The data on product evaluations and country perceptions analyzed together are four-way. This complexity helps explain why, as noted by Gatignon [16], international marketing is a prime research domain for development and application of tailor-made models designed specifically for the data and phenomenon at hand.

This paper presents a model that characterizes both consumer perceptions of countries of origin and the $\mathrm{COO}$ effects of these countries on product evaluation and reveals to what extent and how country perceptions account for product evaluations. This section of the paper explains and justifies at a conceptual level the key components of this model. These components are as follows: $\mathrm{COO}$ effects on product evaluation, relating these effects to consumer perceptions of these countries of origin, and allowing for the effects of nationality of consumers such as home-country bias. It also briefly considers main effects for product, country, and country attribute. 
The model is used to study a wide assortment of countries, product categories, country attributes, and consumer nationalities. This intent guides the design of stimuli and the types of data collected [30].

\section{Perception Effects on Product Evaluation}

Since respondents will consider all combinations of ten product categories and ten source countries, we forego collecting multiple measures of consumer evaluations of every productcountry pairing. Specifically, consumers report whether they would or would not consider purchasing or using a product in each category from each country.

Understanding determinants of product consideration is important. Inclusion in the consideration set can be a more important determinant of choice than selection from the consideration set [19]. It is also challenging, since COO effects are known to be larger for judgments about perceived quality than for indicators of behavioral intention [40]. Finally, asking whether consumers would consider a product based only on its country of origin is more meaningful than asking likelihood of purchase because consumers often form consideration sets based on attributes examined in isolation, whereas final choices entail making tradeoffs among attributes [31,32]. For example, $98 \%$ of our respondents from China would not consider a mobile phone from Indonesia; yet, a majority of them would consider mobile phones from China, India, or Hong Kong. It seems likely that a final choice of phone from these three preferred countries would also depend on other category-specific features and on price. Focusing on product consideration avoids the need to present and manipulate this additional product information, allowing a macrolevel study of diverse product categories and countries of origin.

\section{Explaining COO Effects}

It is possible to obtain a map of COO effects simply by analyzing the consideration data as described above. This would be an example of internal market structure analysis, which explains product evaluations entirely in terms of latent attributes [13-15,20]. While such a map would portray the pattern of $\mathrm{COO}$ effects of countries on products, the axes would be unlabeled, which hinders interpretation, application, and assessment of face validity.

Consumers were also asked whether they agreed or disagreed with each of ten statements applied to each of ten countries. The statements were not product-specific but applied to all products coming from those countries (hence "country attributes"). These data are analyzed simultaneously with the data on product consideration, yielding a single map that portrays countries of origin, product categories, and country attributes.

There are good reasons to expect that perceptions of countries of origin may help explain $\mathrm{COO}$ effects even if these perceptions are not specific to any product category. Verlegh and Steenkamp [40] believe that consumers may recognize that a highly trained and educated workforce can produce high-quality technical products. Roth and Romeo [35] find that consumers' evaluations of a specific product from a specific country are based on the match between product and country in terms of perceived "strengths" of the country and the skills that are needed for manufacturing the product. They also believe that a consistent and favorable product-country match occurs when the perceived strengths of the country are important product benefits or features.

Strong COO effects that are related to country attributes will reveal themselves as dimensions in which products, countries, and country attributes all vary. In addition, there may be country attributes clearly related to country image but unassociated with $\mathrm{COO}$ effects on products; these would reveal themselves as one or more dimensions on which countries and country attributes vary, but not products. Finally, COO effects on product evaluations not accounted for by measured country attributes will be revealed by dimensions in which countries and products vary but country attributes do not. This ability of the model (specified on pages 11-14 with more technical details in the online appendix) to detect systematic $\mathrm{COO}$ effects and systematic country image constructs even though they are unrelated to each other makes the model useful for (1) the discovery of different types of product categories that reveal $\mathrm{COO}$ effects and (2) the discovery of country image indicators that help explain those $\mathrm{COO}$ effects.

We will see to what extent the country perceptions are related to $\mathrm{COO}$ effects for products, and whether the explanation these perceptions provide are consistent with expectations. Just as with the product consideration data, we allow random effects for country perceptions; so, the map needs only to account for systematic patterns in perceptions.

\section{Effects of Consumer Nationality Such as Home-Country Bias}

Country of origin effects include emotional and affective, in addition to cognitive, components, and they are known to vary by consumer nationality [23]. Thus, it is necessary to recognize the effects of consumers' nationality; the model includes four such effects.

The first is to allow for home-country bias. There is a tendency for consumers to evaluate their own country's products relatively more favorably than do foreigners [5]. The construct of consumer ethnocentrism describes a well-observed 
phenomenon among many consumers in favor of homecountry products. Research shows that many consumers consider it virtuous to buy products made in their own country, and consumer ethnocentrism is the major motivation for the decision to purchase domestic products [10,37]. We allow an additive effect for home-country bias that applies whenever a consumer is responding to their own country. We allow the size of this effect to vary by nationality. For each nationality, we estimate a home-bias effect when they are considering products from their country and a separate home-bias effect when they are rating their country on country attributes.

The model also includes nationality main effects for product consideration and country perceptions. Consumers in different countries may differ in how many products they consider overall, and in how inclined they are to agree with statements about country attributes.

The next section provides data specifics such as the countries of origin, product categories, and country attributes included and the nationalities of respondents. The model has no information other than the product consideration and country perceptions provided by consumers. This means that we can use our beliefs about the competitive strengths of countries overall and by product category, and about which product categories and which country attributes ought to be similar, to assess the validity of the findings.

\section{Data}

We examine $\mathrm{COO}$ effects entirely within Asia. Nine countries and one territory were chosen as countries of origin so as to include different levels of economic development and different cultural traditions within Asia: from East Asia (Japan, South Korea, China, and Hong Kong), Southeast Asia (Singapore, Thailand, Malaysia, Indonesia, and Vietnam), and South Asia (India).

Respondents were 96 consumers from each of four of the countries of origin (Japan, China, Malaysia, and Vietnam) that also reflect the diversity of the region. Studying consumers from different countries of origin allows home-country bias to be distinguished from $\mathrm{COO}$ effects. Quota sampling was used for key demographics to increase comparability among the nationalities of respondents. These demographics were sex (half female, half male), age (half 18-33 years old, half 34-48 years old), and social class (half upper class, half middle class). Social class was determined using McKinsey's classification system, which takes into account income, education, type of job, etc.

The product categories were chosen to be highly variable but also familiar to ordinary consumers. They include expensive and technologically complex products (car, television, mobile phone), services (airline, banking services), low-tech products (soft drinks, prepackaged noodles), and fashion goods (jeans, athletic shoes, pop music CD).
The ten country attributes all refer to the country's products in general. Some attributes pertain to product reliability (e.g., "technologically advanced," "good quality," "carefully produced," and "trustworthy") or value (e.g., "good value for money"), while others are less utilitarian (e.g., "fun," "stylish," "fashionable," "approachable," and "keep up with trends"). Table 1 shows all countries of origin, nationalities of respondents, product categories, and country attributes.

The selection of product categories and country attributes reflects a purpose of the analysis, which is to make use of the model's ability to evaluate choices of product categories and country attributes. We expect some product categories to show stronger $\mathrm{COO}$ effects than others and some categories to be more closely related than others, and we have corresponding expectations for the country attributes.

Product consideration, a precursor to choice, has drawn considerable research attention from marketers (e.g., Roberts and Lattin [33]; Allenby and Ginter [3]; Gensch and Soofi [17]). Data on product consideration were obtained by asking "For each product and country listed below, indicate in the box provided whether you would (' 1 ') or would not (' 0 ') consider purchasing or using that product or service from that country." This single question elicited 100 binary responses from each respondent.

Information about country attributes was obtained by asking "For each statement and country below, indicate in the box provided whether you agree (' 1 ') or disagree (' 0 ') with the statement about products coming from that country." This question yielded another 100 binary responses, since each of the same ten countries from question 1 were paired with the ten country attributes (cf. Table 1).

Following pretesting in China, the surveys were translated into each nationality's predominant language and were personally administered using the services of McKinsey AsiaPacific Marketing Practice. There were no missing data. Thus, there were 200 binary responses for each of the 386 subjects or 76,800 responses in all.

\section{Model Specification}

This section builds upon the conceptual development with precise specification of the model estimated. The core of the model estimates the locations of countries of origin, products, and country attributes in $\mathrm{M}$ latent dimensions, with $\mathrm{M}$ determined by the data. The model is designed to let the data reveal relationships within and among products, countries, and country attributes.

\subsection{Product Consideration}

We use a utility-theoretic model to account for whether a respondent would consider purchasing or using a particular product from a particular country (these data are provided by 
Table 1 Countries of origin, product categories, country attributes, and nationalities of respondents

\begin{tabular}{lll}
\hline Countries of origin & Products & Country attributes \\
\hline Japan (Jp) & Television (TV) & Technologically advanced (Tchnl) \\
Korea (Kr) & Car (Car) & Good quality (Qulty) \\
Hong Kong (HK) & Mobile phone (MblP) & Carefully produced (CrflP) \\
China (Ch) & Banking services (Bnkn) & Trustworthy (Trstw) \\
Singapore (Sn) & Airline (Arln) & Good value for money (Value) \\
Thailand (Th) & Prepackaged noodles (Ndls) & Approachable (Apprc) \\
Malaysia (Ml) & Athletic shoes (AthS) & Keeps up with trends (Contmp) \\
Indonesia (Indn) & CD of pop music (CD) & Fun (Fun) \\
India (Indi) & Soft drink (SfD) & Stylish (Styls) \\
Vietnam (Vt) & Jeans (Jens) & Fashionable (Fshnb) \\
\hline
\end{tabular}

Note: The nationalities of respondent are shown in bold the first question in the survey). For a product to be considered, its utility for a respondent must exceed some threshold that is allowed to be product-specific. Equivalently, relative utility, defined as utility minus threshold, must exceed zero; that is,

Consideration $_{\mathrm{ipcn}}=1$ if and only if RelativeUtility $\mathrm{rpcn}_{\mathrm{rpn}}$

$$
\equiv\left(\text { Utility }_{\text {rpcn }}-\text { Threshold }_{\mathrm{p}}\right)>0,
$$

where " $r$ " denotes the respondent, " $p$ " the product category, "c" the country of origin, and " $n$ " the nationality of the respondent. Our model of relative utility is

$$
\begin{aligned}
\text { RelativeUtility }_{\mathrm{rpcn}}= & \mu_{1}+\alpha_{\mathrm{n} 1}+\delta_{\mathrm{n} 1} \mathrm{I}(\mathrm{c}=\mathrm{n})+\eta_{\mathrm{n} 1} \beta_{\mathrm{p}} \gamma_{\mathrm{c}}{ }^{\prime}-\zeta_{\mathrm{p}} \\
& +\varphi_{\mathrm{pcn}}+\varepsilon_{\mathrm{rpcn}}
\end{aligned}
$$

where the subscript " 1 " is used to distinguish parameters for this first question from analogous parameters for the second question.

This model includes a grand mean, $\mu_{1}$, a main effect for nationality of the respondent, $\alpha_{n 1}$, and a nationality-specific effect of nation pride, $\delta_{n 1}$, which applies whenever a respondent is evaluating a product made in his or her own country, $\mathrm{I}(\mathrm{c}=\mathrm{n})$. That is, $\mathrm{I}(\cdot)$ is the indicator function, equal to 1 whenever its argument is true and 0 otherwise.

The expression $\beta_{p} \gamma_{c}{ }^{\prime}$ accounts for regularities in $\mathrm{COO}$ effects and is the heart of the model. Both $\beta_{p}$ and $\gamma_{c}$ are row vectors with $\mathrm{M}$ elements that provide the locations of products and countries, respectively, in an M-dimensional map. Country main effects are excluded from the model so that this map must also explain why more products are considered from some countries than others.

The parameter $\eta_{\mathrm{n} 1}$, which must be positive, allows the extent to which the map accounts for $\mathrm{COO}$ effects to vary by nationality of the respondent - as $\eta_{\mathrm{n} 1}$ gets more positive, the map better explains product consideration. We refer to $\eta_{\mathrm{n} 1}$ as map relevance for this first question. The term $\zeta_{p}$ represents the product-specific threshold. Consumers will consider fewer countries for products with high thresholds. Finally, $\varphi_{\mathrm{pcn}}$ and $\varepsilon_{\text {rpcn }}$ are independently and identically distributed (i.i.d.) logistic random variables. Detailed explanation can be found in the online appendix.

\subsection{Country Image}

The second question is similar in essential respects to the first, and this similarity is reflected in our modeling of these data. Respondents indicate whether they agree (" 1 ") or disagree (" 0 ") with each statement about products coming from each country. For simplicity, we refer to these statements, such as "technologically advanced," "fashionable," and "trustworthy," as country attributes even though they describe products in general from that country. We assume that, for a statement to be agreed to, the respondent's degree of agreement must exceed a threshold, which is also allowed to be attribute-specific. Equivalently, relative agreement must exceed zero. That is,

$$
\begin{aligned}
\text { Agree }_{\text {racn }} & =1 \text { if and only if RelativeAgreement } \\
& \equiv\left(\text { Agreement }_{\text {racn }}-\text { Threshold }_{\mathrm{a}}\right)>0,
\end{aligned}
$$

We model relative agreement as

$$
\begin{aligned}
\text { RelativeAgreement } & \mu_{\mathrm{racn}}= \\
& \mu_{2}+\alpha_{\mathrm{n} 2}+\delta_{\mathrm{n} 2} \mathrm{I}(\mathrm{c}=\mathrm{n})+\eta_{\mathrm{n} 2} \beta_{\mathrm{a}} \gamma_{\mathrm{c}}{ }^{\prime}-\zeta_{\mathrm{a}} \\
& +\varphi_{\mathrm{can}}+\varepsilon_{\mathrm{racn}} .
\end{aligned}
$$

The same notation is used here as for question 1, except that the subscript "a" denotes country attribute and the subscript " 2 " is used, where needed, to signify that the parameter estimates differ by question. For example, the nationality main effects of question 2, $\alpha_{n 2}$, are different from those of question $1, \alpha_{n 1}$. Three new sets of parameters are introduced for this question, the attribute-specific thresholds (denoted $\zeta_{\mathrm{a}}$, as distinct from the product-specific thresholds $\zeta_{p}$ of question 1), the locations of country attributes in the M-dimensional map 
$\left(\beta_{\mathrm{a}}\right)$, and the random effects $\varphi_{\text {acn }}$ which are allowed to have a different variance for this question than for question 1.

Responses to both questions need to be estimated simultaneously, because the estimated locations of the ten countries in the map, $\left(\gamma_{\mathrm{c}}\right)$, are common to both questions. If the country attributes explain $\mathrm{COO}$ effects, then country attributes and products will vary in the same dimensions; otherwise, they will vary in different dimensions. Model identification information is provided in the technical appendix.

\section{Analysis and Results}

The data were analyzed by Bayesian methods using WinBUGSversion 1.4.3 [29] and R version 2.8.1 (R [12]). Bayesian analysis is appropriate due to the presence of 400 random effects for evaluations $\left(\varphi_{\mathrm{pcn}}\right)$ and another 400 for perceptions $\left(\varphi_{\text {acn }}\right)$. We began by estimating a onedimensional map (at least one dimension is required to explain COO main effects). Adding a second dimension improved DIC by 15.9 , adding a third dimension improved DIC by a further 12.0, but adding a fourth dimension improved DIC by only 2.6. We settled on a three-dimensional solution. The justification for this as well as the details of this solution can be found in the technical appendix.

\subsection{Market Structure Map in Terms of Country of Origin}

Our dataset of 76,800 observations allowed detection of three dimensions for $\mathrm{COO}$ effects. The first two dimensions explain on average 43.5 and $54.8 \%$ of the variance, while the residual third dimension continues to explain only $1.8 \%$. Furthermore, only one attribute location and only one product location are appreciably different from zero on the third dimension. Thus, this third dimension has distinguished two items that are somewhat distinct from other 18 . We begin by considering the first two dimensions.

To improve interpretability, the first two dimensions of the map were rotated so as to maximize alignment of country attribute loadings to dimensions according to the varimax criterion. This rotation was performed for each of the 100,000 iterations of the simulates used for inference.

The estimates and posterior standard deviations for the locations of countries, products, and country attributes are shown in Tables 2 and 3. However, these estimates are better interpreted and assessed graphically. Figure 1 portrays the relation of the countries to product categories and country attributes on the first two dimensions. The countries (shown in black and bold) are plotted using the scale values shown at the left and bottom of the figure ("country units"). The product categories (red) and country attributes (blue and italic) are plotted using the scale values show to the right and at the top of the figure ("product/country attribute units").
All abbreviations used in the figures are defined in Table 1. The axes labels, fashion and technology, reflect the country attributes strongly associated with each dimension. Since the plot preserves the orthogonality of products and country attributes, angles among products and country attributes are meaningful, as are distances between countries. Furthermore, it is possible to reproduce the fitted competitive positions of the countries for any product or on any country attribute through a process of projection [18].

From Fig. 1, we can make several observations about these ten Asian countries. The countries tend to lie along a single line ("principal axis") from lower left to upper right. A partial exception to this is Japan, which lies above that line. This line seems to correspond to what might be termed economic development, with Japan positioned highest along this line, followed by Korea, Hong Kong, China and Singapore, and Vietnam at the bottom. Recalling that the four countries chosen as sources of respondents were Japan, China, Malaysia, and Vietnam, we see that these countries reflect the variability in all ten countries very well - they rank first, fourth, seventh, and tenth along this predominant continuum.

An indication that this continuum corresponds to economic development is provided by a regression analysis of country locations along this principal axis against two indicators of economic development provided by the International Monetary [21]: log gross domestic product and log per capita gross domestic product. The first indicator reflects the overall size of the economy, and the second reflects the standard of living within that economy. The regression as a whole has an $R^{2}$ of .86 and an overall $p$ value of .001 . The two estimated coefficients are both positive and have $p$ values of .011 and .001 , respectively. A second regression of country departures from the lower left upper right continuum against these same two indicators of economic development has an $R^{2}$ of only .08 and an overall $p$ value of .76, indicating that country departures from the principal axis are unrelated to these indicators of economic development (the regression of country locations on the third dimension to these economic indicators is also statistically insignificant).

To further assess the face validity of the map and to illustrate how it is interpreted, we consider in detail the countries' competitive positions vis-à-vis two product categories: TVs and jeans. Figure 2 portrays the fitted competitive positions of the countries for the TV product category. This is given by the orthogonal projection of the countries onto the line that passes from the origin through TV. The distance of a country from this line is irrelevant - all that matters is the position of a country on the line. The fitted $\mathrm{COO}$ effects of the countries for TVs are given, up to an additive constant, by the distances from the origin of the country projections onto the TV line (measured in country units) times the distance of TV from the origin (measured in product/country attribute units). We see from Fig. 2, for example, that Japan lies rather far from the line 
Table 2 Estimates of country attribute and product locations

\begin{tabular}{|c|c|c|c|c|c|c|}
\hline \multirow[t]{2}{*}{ Country attribute $\left(\beta_{\mathrm{a}}\right)$ (abbreviation) } & \multirow[t]{2}{*}{ Product $\left(\beta_{\mathrm{p}}\right)$ (abbreviation) } & \multicolumn{3}{|l|}{ Location } & \multicolumn{2}{|c|}{ Country variance ${ }^{\mathrm{a}}$} \\
\hline & & Dim. 1 & Dim. 2 & Dim. 3 & Dims 1 and 2 & $\operatorname{Dim} 3$ \\
\hline \multirow[t]{3}{*}{ Technologically advanced (Tchnl) } & & $-.02(.05)$ & $.46(.05)$ & $.04(.13)$ & 2.33 & .00 \\
\hline & Television (TV) & $-.01(.08)$ & $.39(.06)$ & $.10(.14)$ & 1.73 & .00 \\
\hline & Car (Car) & $.04(.08)$ & $.34(.06)$ & $-.23(.14)$ & 1.66 & .02 \\
\hline Good quality (Qulty) & & $.05(.07)$ & $.36(.06)$ & $-.01(.14)$ & 1.90 & .00 \\
\hline Carefully produced (CrflP) & & $.05(.07)$ & $.29(.06)$ & $.04(.14)$ & 1.30 & .00 \\
\hline Trustworthy (Trstw) & & $.05(.07)$ & $.29(.06)$ & $.09(.14)$ & 1.30 & .00 \\
\hline \multirow[t]{3}{*}{ Good value for money (Value) } & & $.10(.08)$ & $.17(.07)$ & $.05(.15)$ & .76 & .00 \\
\hline & Mobile phone (MblP) & $.16(.07)$ & $.25(.06)$ & $-.03(.15)$ & 1.74 & .00 \\
\hline & Banking services (Bnkn) & $.11(.08)$ & $.08(.07)$ & $-.20(.17)$ & .37 & .01 \\
\hline Approachable (Apprc) & & $.17(.08)$ & $.08(.07)$ & $.37(.13)$ & .65 & .04 \\
\hline \multirow[t]{2}{*}{ Keeps up with trends (Cntmp) } & & $.27(.07)$ & $.09(.06)$ & $.08(.15)$ & 1.24 & .00 \\
\hline & Airline (Arln) & $.17(.08)$ & $.04(.07)$ & $-.45(.14)$ & .48 & .06 \\
\hline Fun (Fun) & & $.23(.06)$ & $.03(.06)$ & $.05(.15)$ & .64 & .00 \\
\hline \multirow[t]{2}{*}{ Stylish (Styls) } & & $.34(.07)$ & $.04(.06)$ & $-.15(.15)$ & 1.37 & .01 \\
\hline & Prepackaged noodles (Ndls) & $.17(.07)$ & $.01(.07)$ & $.25(.15)$ & .32 & .02 \\
\hline \multirow[t]{5}{*}{ Fashionable (Fshnb) } & & $.41(.07)$ & $-.04(.05)$ & $-.10(.15)$ & 1.28 & .00 \\
\hline & Athletic shoes (AthS) & $.25(.06)$ & $-.05(.06)$ & $.03(.14)$ & .38 & .00 \\
\hline & CD of pop music (CD) & $.35(.06)$ & $-.07(.06)$ & $.01(.15)$ & .74 & .00 \\
\hline & Soft drink (SftD) & $.21(.06)$ & $-.05(.06)$ & $.08(.15)$ & .24 & .00 \\
\hline & Jeans (Jens) & $.35(.06)$ & $-.13(.06)$ & $.04(.14)$ & .48 & .00 \\
\hline
\end{tabular}

Note: Parentheses are used to identify attribute abbreviations used in the map and posterior SDs of location parameters. Posterior means more than two SDs away from zero are shown in bold

${ }^{a}$ Variance in countries on each item over first two dimensions and on the third dimension only

but nevertheless has the highest position on that line (it is the highest and not the lowest because it is furthest in the direction

Table 3 Estimates for country locations

\begin{tabular}{llll}
\hline Country (abbreviation) & \multicolumn{2}{l}{ Location $(\gamma)$} & \\
\cline { 2 - 4 } & \multicolumn{1}{l}{ Dim. 1 } & \multicolumn{1}{l}{ Dim. 2 } & \multicolumn{1}{l}{ Dim. 3 } \\
\hline Japan (Jp) & $3.89(.67)$ & $7.51(.47)$ & $.30(.25)$ \\
Korea (Kr) & $4.09(.39)$ & $3.63(.41)$ & $.05(.28)$ \\
Hong Kong (HK) & $3.26(.30)$ & $1.18(.41)$ & $-.61(.26)$ \\
China (Ch) & $1.66(.35)$ & $.95(.36)$ & $.72(.31)$ \\
Singapore (Sn) & $.87(.33)$ & $.76(.32)$ & $-.64(.30)$ \\
Thailand (Th) & $-.02(.34)$ & $-.92(.33)$ & $.25(.32)$ \\
Malaysia (Ml) & $-3.41(.45)$ & $-2.07(.46)$ & $-1.00(.26)$ \\
Indonesia (Indn) & $-3.01(.44)$ & $-3.50(.45)$ & $.08(.31)$ \\
India (Indi) & $-3.66(.47)$ & $-3.39(.50)$ & $.16(.34)$ \\
Vietnam (Vt) & $-3.67(.50)$ & $-4.13(.47)$ & $.70(.28)$ \\
\% Variance explained & 43.5 & 54.8 & 1.8 \\
\hline
\end{tabular}

Note: Parentheses are used to identify country abbreviations used in the map (column 1) and posterior standard deviations of parameters (elsewhere). Posterior means more than two posterior standard deviations away from zero are shown in bold of the arrow pointing at TV). We also see that the countries are very spread out along this line (and also TV is far from the origin), indicating strong $\mathrm{COO}$ effects for TVs. Korea holds a distant second place in terms of TVs but is still well ahead of the rest, and Vietnam is at the bottom.

Figure 2 also shows another product category, car, which lies in the same general direction as TVs, as well as country attributes that also lie in that direction. Angles among products and country attributes are meaningful. In particular, if they lie in the same direction, they are strongly positively related, if in the opposite direction, strongly negatively related, and if their directions are at right angles they are unrelated. The strong positive relation between TVs and cars is entirely sensible, as are their strong positive relations with the country attributes "technologically advanced" (Tchnl), "good quality" (Qulty), "carefully produced" (CrflP), and "trustworthy" (Trstw). These attributes are important for technically complex and costly products such as TVs and cars. They are also important for mobile phone (MblP), which is more strongly related to the vertical axis than to the horizontal.

Figure 3 uses the same map of Fig. 1 to focus in on the competitive position of these countries vis-à-vis the jeans product category. Now, competitive position is determined 


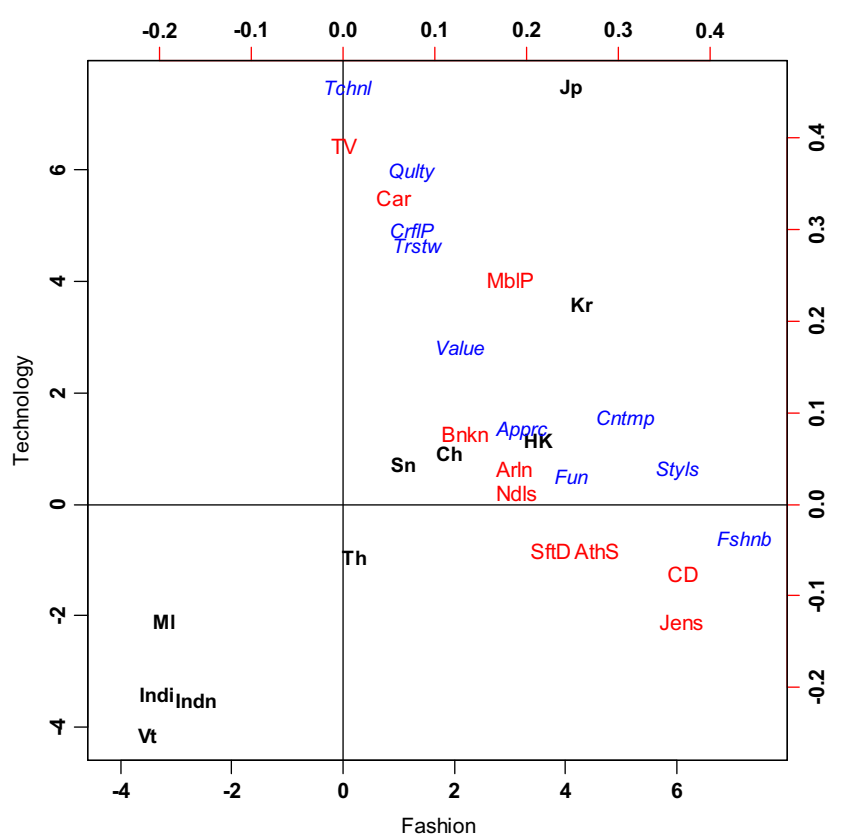

Fig. 1 Competitive map of countries for all products and country attributes. Note: labels in black and bold are Asian countries; those in blue and italic are country attributes and those in red are product categories. All labels in the figure are defined in Table 1

by a line running from the origin through jeans, which lies largely to the right and somewhat downwards. The projections of the countries onto this line show that the countries are less spread out (and jeans are also somewhat closer to the origin), and that Japan is no longer in the strongest competitive position. Rather, Hong Kong and Korea are now in the best position, with Japan only tied with China, Singapore, and

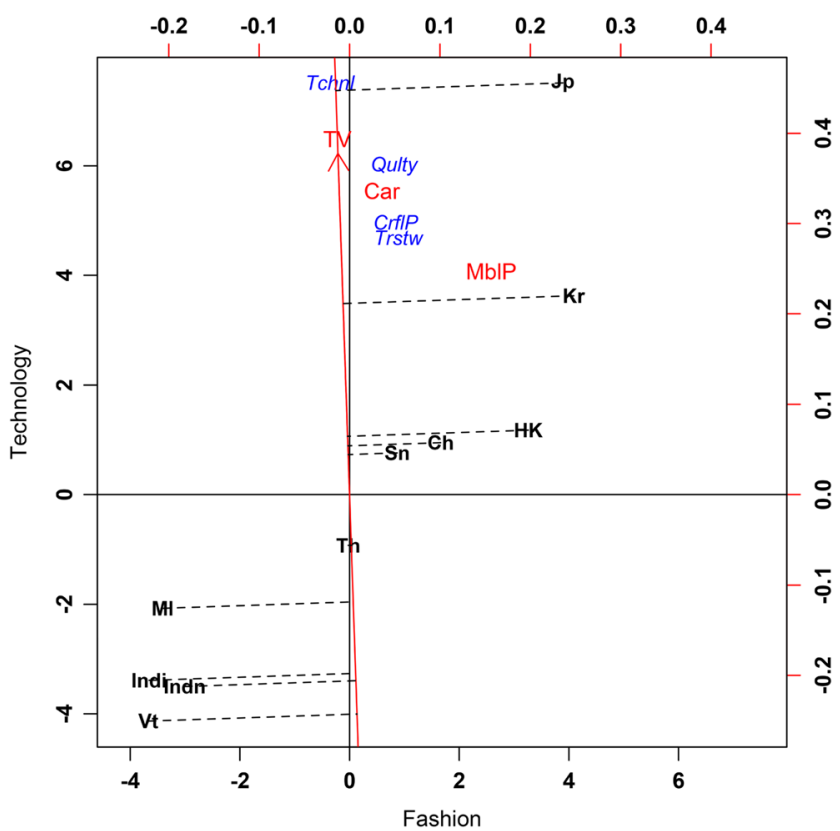

Fig. 2 Focusing on country competitive positions for tvs. Note: labels in black and bold are Asian countries; those in blue and italic are country attributes and those in red are product categories

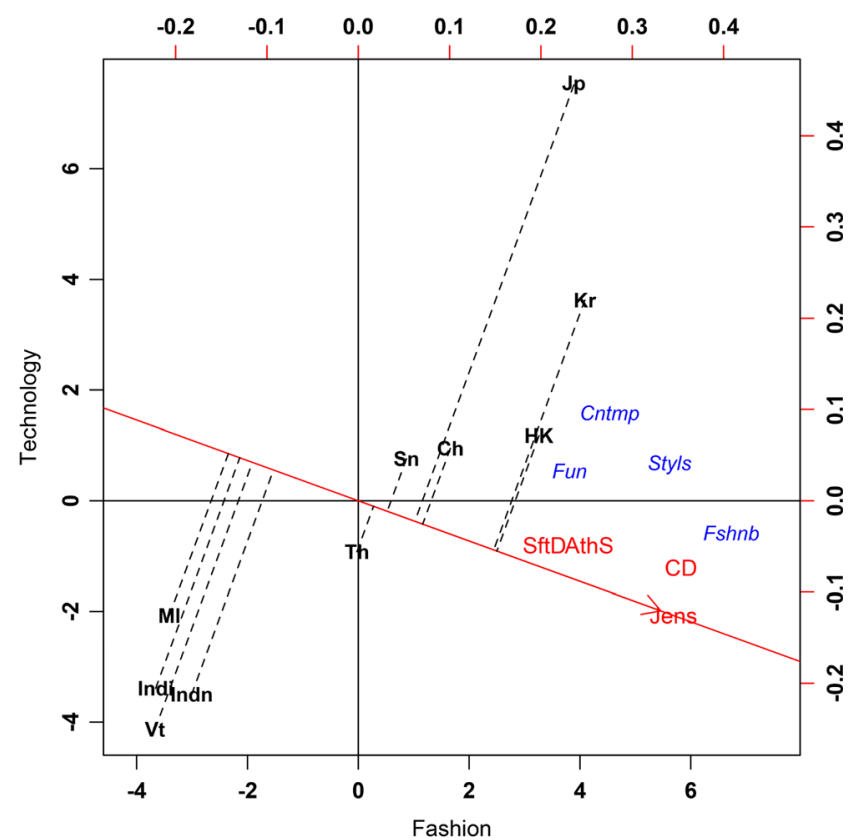

Fig. 3 Focusing on country competitive positions for jeans. Note: labels in black and bold are Asian countries; those in blue and italic are country attributes and those in red are product categories

Thailand. Vietnam remains near the bottom. The figure also includes products and country attributes that lie in the same direction as jeans. We see that the competitive positions of the ten countries would be nearly identical for CDs of pop music, athletic shoes, and soft drinks. The attributes important for TVs and cars are largely irrelevant for these products. Instead, the country attributes that matter most are "fashionable" (Fshnb), "stylish" (Styls), "fun" (Fun), and to a lesser extent "keep up with trends" (Cntmp).

Figures 2 and 3 are both selected portions of Fig. 1, which can be used to produce fitted competitive position of the countries for any of the other products. Mobile phones (MblP) lie in a direction in between TVs and jeans, reflecting that fashion matters as well as technology for this product category. Competitive positions on country attributes may be reproduced in the same manner as for product categoriesfirst, a line is drawn through the country attribute and the origin, the countries' positions on the line are obtained by orthogonal projection onto that line, and their fitted $\mathrm{COO}$ effects are given, up to an additive constant, by their projected distances from the origin (in country units) times the distance of the country attribute from the origin (in product/country attribute units). The estimated sizes of $\mathrm{COO}$ effects for all products and country attributes as implied by the map are given by the second-to-last column in Table 2, which shows the variances of the countries' fitted values. Large variances correspond to strong $\mathrm{COO}$ effects. We see that the smallest $\mathrm{COO}$ effects are for soft drinks and prepackaged noodlesproduct categories plotted close to the origin in Fig. 1 and lying in a direction in which the countries vary less - a finding 
that is not surprising. COO effects are largest for "technologically advanced," "good quality," televisions, cars, and mobile phones, which is not surprising either.

Considering in detail the competitive positions of these countries vis-à-vis TVs and cars versus jeans and pop music CDs allows clarification of the second dimension that goes beyond "economic development." It highlights an opportunity for countries to differ on the extent to which they specialize in being strong on technology (Japan) versus fashion (Hong Kong). This is good news for Asian countries because it shows that competitive position is not simply one-dimensional with one country dominant. Even just two dimensions suffice to allow the existence of an efficiency frontier [26], with numerous countries in the best competitive position for different product categories. The fact that some product categories show little $\mathrm{COO}$ effects is also good news for the less-developed countries appearing in the lower left quadrant of the map. These countries have a competitive advantage of lower labor costs that is not erased by strong $\mathrm{COO}$ effects for such product categories.

\subsection{Effects Pertaining to Nationality of Respondents}

Table 4 shows the estimates for parameters pertaining to nationality: main effects, map relevance, and home country effects for both questions. The estimates are similar across the two questions. The Vietnamese are most different- they have the lowest main effects (meaning they give the fewest $1 \mathrm{~s}$ overall), the highest map relevance, and the highest degrees of home country bias. The Malaysians are nearly the opposite: they give the most 1's overall, have relatively low map relevance and lower (but still positive) home country bias. Japan and China are intermediate, although Japan has the lowest map relevance.

\subsection{Estimated Thresholds for Products and Country Attributes}

Table 5 shows the estimates for product-specific thresholds for question 1 and the country attribute thresholds for question 2 .
The thresholds are sorted in the table from highest to lowest within each question. The differences in thresholds are greater for products than those for country attributes. Cars have the highest threshold, which means that fewer countries are considered for cars than for the other products. Higher than average thresholds are also obtained for banking services, mobile phones, and televisions. The lowest threshold is obtained for prepackaged noodles. Such results seem entirely reasonable.

As for country attributes, the fewest countries are described as offering products that keep up with trends or that are carefully produced. The most countries are said to offer good value for money, which makes sense since countries that produce lower quality products produce them more cheaply.

\section{Discussion}

A model designed to detect and explain brand perception effects determined statistically that three dimensions are needed to account for systematic (i.e., nonrandom) relationships among ten countries of origin, ten product categories, and ten country attributes. The third dimension explains only $1.8 \%$ of the variance accounted for by all three dimensions and is strongly related to only one product category and one country attribute. However, the first two dimensions are strongly related to countries, product categories, and country attributes. These two dimensions are clearly and plausibly related to country attributes and readily interpreted as fashion and technology leadership. The relationships of the product categories to each other and to these dimensions also possess high face validity, as do the positions of the countries of origin in terms of overall competitive strength and their associations with the two dimensions.

These findings are consistent with widely observed country product category interactions $[9,39]$ and support the argument of Leonidou et al. [28] that consumers' evaluations of country of origin can be complex and sophisticated.

The structure of the competitive map mirrors (by design) a plausible account of $\mathrm{COO}$ effects - consumers favor products
Table 4 Estimates for nationalities of respondents: main effect, map relevance, and homecountry bias

\begin{tabular}{|c|c|c|c|c|c|c|}
\hline \multirow{2}{*}{$\begin{array}{l}\text { Nationality } \\
\text { (abbreviation) }\end{array}$} & \multicolumn{2}{|c|}{ Main effect $(\alpha)$} & \multicolumn{2}{|c|}{ Map relevance $(\eta)$} & \multicolumn{2}{|c|}{ Home-country bias $(\delta)$} \\
\hline & Ques. 1 & Ques. 2 & Ques. 1 & Ques. 2 & Ques. 1 & Ques. 2 \\
\hline Malaysia (Ml) & $.97(.06)$ & $.90(.06)$ & $.84(.06)$ & $.73(.04)$ & $2.45(.21)$ & $1.82(.21)$ \\
\hline China (Ch) & $.28(.06)$ & $.50(.06)$ & $1.12(.07)$ & $1.17(.06)$ & $2.97(.22)$ & $1.44(.22)$ \\
\hline Japan (Jp) & $.56(.06)$ & $-.13(.06)$ & $.64(.06)$ & $.74(.06)$ & $4.05(.27)$ & $2.49(.27)$ \\
\hline Vietnam (Vt) & $-1.81(.09)$ & $-1.27(.08)$ & $1.67(.11)$ & $1.61(.09)$ & $5.36(.34)$ & $4.52(.34)$ \\
\hline
\end{tabular}

Notes: Posterior standard deviations are shown in parentheses. Estimates more than two standard deviations away from zero (away from one in the case of map relevance) are shown in bold. In addition, the estimate for the intercept for the first question $\left(\mu_{1}\right)$ is $-1.94(\mathrm{SD}=.04)$, and for the second question $\left(\mu_{2}\right)$ is $-1.70(\mathrm{SD}=.04)$. The random effect variance estimates were $.28(\mathrm{SD}=.02)$ and $.31(\mathrm{SD}=.02)$ for the first and second questions, respectively 
Table 5 Estimates of thresholds ( $\zeta)$

\begin{tabular}{lllr}
\hline Product (abbreviation) & Threshold & Country attribute (abbreviation) & Threshold \\
\hline Car (Car) & $.70(.10)$ & Keeps up with trends (Cntmp) & $.33(.11)$ \\
Banking services (Bnkn) & $.56(.10)$ & Carefully produced (CrflP) & $.29(.09)$ \\
Mobile phone (MblP) & $.41(.09)$ & Stylish (Styls) & $.15(.10)$ \\
Television (TV) & $.25(.09)$ & Trustworthy (Trstw) & $.15(.09)$ \\
CD of pop music (CD) & $-.14(.09)$ & Fashionable (Fshnb) & $-.05(.10)$ \\
Jeans (Jens) & $-.25(.08)$ & Technologically advanced (Tchnl) & $-.07(.10)$ \\
Airline (Arln) & $-.30(.09)$ & Good quality (Qulty) & $-.13(.10)$ \\
Soft drink (SftD) & $-.32(.09)$ & Fun (Fun) & $-.14(.09)$ \\
Athletic shoes (AthS) & $-.36(.08)$ & Approachable (Apprc) & $-.17(.09)$ \\
Prepackaged noodles (Ndls) & $-.56(.09)$ & Good value for money (Value) & $-.35(.10)$ \\
\hline
\end{tabular}

Note: Posterior standard deviations are shown in parentheses. Posterior means more than two posterior standard deviations away from zero are shown in bold coming from a certain country because they believe that country is particularly good at providing what is most important to consumers for that product category. Fashion is more of an issue for jeans, and technology is more salient for cars. Although these findings are based entirely on Asian consumers' views of Asian countries, they are universally interpretable. Many consumers would agree that Japan is best and Korea second as suppliers of automobiles due to their strong technological capabilities. Many would also not presume that their strong competitive positions for cars would carry over to jeans and athletic shoes. It is also not surprising that the wide variation in economic development of these countries impacts their overall competitive positions.

In sum, we have found for the Asian region that there are systematic, and not simply idiosyncratic, differences in $\mathrm{COO}$ effects across diverse product categories. These systematic differences are multidimensional, result in understandable groupings of product categories and countries, interpretable in terms of country image as technology and fashion expertise. Further applications of this methodology for other regions and product categories are necessary, but it appears that country of origin is a multidimensional construct that transcends product categories and regions, consisting of the two dimensions fashion and technology leadership, and we demonstrate this empirically.

\subsection{Implications for COO}

An understanding of the multidimensionality of $\mathrm{COO}$ can help both national policymakers and product managers. In the short term, both types of decision makers can ensure that they act in accordance with their countries or products competitive position. For example, Korea and Hong Kong should recognize that many Asian consumers view them as trend leaders due to their comparative strength in fashion leadership. They have been able to build up this fashion expertise based on the popularity of TV soap operas, films, and music which emanate from both countries and are influential around the region [11]. Further economic and trade policies should help ensure that investments continue to be made in popular culture products and that strong fashion-related brands are supported.

In the long run, consumer perception of countries of origin can change dramatically, as $\mathrm{COO}$ perceptions are dynamic not static [4]. Such change benefits from an evolutionary perspective [2]. "Made in Japan" as a label has experienced vast change in perception over the past 50 years from highly negative to highly positive. How did this occur, especially within a region that had negative views of Japan related to Japan's role in the region before and during WWII? As demonstrated in our map, Japan pursued and attained technological leadership within the region, which had strong effects on certain product category $\mathrm{COO}$ evaluations. Technological leadership is less culture bound than fashion and trend leadership. Iwabuchi [22] points out that one of the ways Japan was able to achieve technological leadership was to make their products "odorless," meaning that they do not carry overt cultural symbols to identify them as Japanese.

It is important for policy makers to recognize that $\mathrm{COO}$ is multidimensional and that this implies that countries can specialize and differentiate, resulting in more widespread prosperity than is possible for one-dimensional competition where only one country is perceived as best for all products $[25,26]$. For example, it seems doubtful that Korea should strive to become more like Japan when it already matches Japan on fashion leadership and such imitation would only intensify competition between the two countries. Korea is better positioned for products such as mobile phones that call for a mix of technological and fashion expertise. Long-term positioning can also be meaningful for emerging markets such as India and Vietnam, which presently have weak competitive positions for Asian consumers. However, these countries are growing rapidly and achieving cultural influence in the region [7]. It is easy to underestimate the rate at which consumer perceptions of countries can change. 
In sum, by revealing the nature of the multidimensionality of the $\mathrm{COO}$ construct, we can map the marketplace structure of the Asian region and understand why the structure appears as it does. We can utilize these insights to generate guidance for emerging markets to invest in product development based in part on the type of leadership one's country of origin is perceived to have. Thus, conceptualizing the $\mathrm{COO}$ construct in the way we have reveals new insights on brand perception which are needed given the complexities of an interconnected, globalized world.

\subsection{Model Limitations and Future Research}

Limitations of the model warrant acknowledgment. By design, product category is chosen as the level of analysis. This allows the investigation of widely varying product categories, but for managers, a more detailed analysis within their category may be desired. Consumers can have perceptions of countries on price just as on any other attribute, and our model would treat price as such, but managers will want to know to what extent a reduced or increased price can offset negative $\mathrm{COO}$ associations, and this too would require a category-specific analysis. Our model allows for differences by nationality of consumers but does not explain why these differences exist. Researchers primarily interesting in understanding such differences would want to refine the model accordingly. The same can be said for investigators into the different ways in which countries can be associated with products, such as place of design or of manufacture.

However, the model is robust in important ways. Poor choices of country attributes mean that dimensions of $\mathrm{COO}$ effects would be inadequately explained, but the model will reveal these deficiencies. Choosing very different product categories from those studied here could of course reveal a different aspect of $\mathrm{COO}$, which it should. The allowance by the model for idiosyncratic variation by product category means that such variation will not be mistaken for a fundamental part of the $\mathrm{COO}$ construct.

Other uses include investigation of other types of products such as services. We included two services, but others might wish to study only services or an equal number of services and products. Finally, country product images will change over time; they are dynamic in nature. Future research should investigate whether new dimensions will emerge in Asia over time, and how the various countries migrate on the dimensions over time. There is also a need to investigate other geographic regions and important markets to reveal the dimensions which make up country of origin, and compare and contrast them to the dimensions in Asia. Future research should also examine within country differences, to compare and contrast them to the across country differences we discuss here.
Acknowledgments The authors thank Terry Elrod for his help with the modeling. The authors also thank Adam Finn, Robert Fisher, Gerald Häubl, Joffre Swait and Katharina Zeugner-Roth for their helpful comments.

\section{References}

1. Ahmed SA, d'Astous A (2008) Antecedents, moderators and dimensions of country-of-origin evaluations. Int Mark Rev 25(1): 75-106

2. Aldrich HE (1999) Organizations Evolving. Sage Publications, Newbury Park

3. Allenby GM, Ginter JL (1995) The effects of in-store displays and feature advertising on consideration sets. Int J Res Mark 12(1):6780

4. Beverland M, Lindgreen A (2002) Using country of origin in strategy: the importance of context and strategic action. J Brand Manag 10(2):147-167

5. Bilkey WJ, Nes E (1982) Country-of-origin effects on product evaluations. J Int Bus Stud 13(1):89-99

6. Carroll JD, Arabie P (1980) Multidimensional-scaling. Annu Rev Psychol 31:607-649

7. Cayla J, Eckhardt GM (2007) Asian brands without borders: regional opportunities and challenges. Int Mark Rev 24(4):444

8. Cayla J, Eckhardt GM (2008) Asian brands and the shaping of a transnational imagined community. J Consum Res 35(2):216

9. Chattalas M, KramerT TH (2008) The impact of national stereotypes on the country of origin effect: aconceptual framework. Int Mark Rev 25(1):54-74

10. Chryssochoidis G, KrystallisA PP (2007) Ethnocentric beliefs and country-of-origin (coo) effect: impact of country, product and product attributes on greek consumers' evaluation of food products. Eur J Mark 41(11/12):1518-1544

11. Chua BH (2004) Conceptualizing an east asian popular culture. Inter-Asia Cult Stud 5(2):200-221

12. Development Core Team R (2008) R: alanguage and environment for statistical computing. R Foundation for Statistical Computing, Vienna

13. Elrod T (1991) Internal market structure analysis: recent developments and future prospects. Mark Lett 2(3):253-266

14. Elrod T, Russell GJ, Shocker AD, Andrews RL, Bacon L, Bayus BL, Carroll JD, Johnson RM, Kamakura WA, Lenk P, Mazanec JA, Rao VR, Shankar V (2002) Inferring market structure from customer response to competing and complementary products. 5 th Triennial Symposium on Choice Modeling, Vol. 13

15. Erdem T (1996) A dynamic analysis of market structure based on panel data. Mark Sci 15(4):359-378

16. Gatignon H (2000) Commentary on Peter Leeflang and Dick Wittink's 'building models for marketing decisions: past, present and future'. Int J Res Mark 17(2-3):209-213

17. Gensch DH, Soofi ES (1995) Information-theoretic estimation of individual consideration set. Int J Res Mark 12(1):25-38

18. Gower JC, Hand DJ (1996) Biplots. Chapman \& Hall, London

19. Hauser JR, Tellis GJ, Griffin A (2006) Research on innovation: a review and agenda for marketing science. Mark Sci 25(6):687-717

20. Inman JJ, Park J, Sinha A (2004) A dynamic choice map approach to modeling attribute-Level varied behavior among stockkeeping units. J Mark Res 45(1):94-103

21. International Monetary Fund (2008) World economic outlook database

22. Iwabuchi K (2002) Recentering globalization: popular culture and Japanese transnationalism. Duke University Press, Durham 
23. Johansson JK, Douglas SP, Nonaka I (1985) Assessing the impact of country of origin on product evaluations: a new methodological perspective. J Mark Res 22(4):388-396

24. Lala V, Allred AT, Chakraborty G (2009) A multidimensional scale for measuring country image. J Int Consum Mark 21(1):51-66

25. Lancaster K (1971) Consumer demand: a new approach. Columbia University Press, New York

26. Lancaster K (1979) Variety, equity, and efficiency. Columbia University Press, New York

27. Laroche M, Papadopoulos N, Heslop LA, Mourali M (2005) The influence of country image structure on consumer evaluations of foreign products. Int Mark Rev 22(1):96-115

28. Leonidou LC, Palihawadana D, Talias MA (2007) British consumers' evaluations of US versus Chinese goods - a multi-level and multi-cue comparison. Eur J Mark 41(7-8): 786-820

29. Lunn DJ, Andrews T, Best N, Spiegelhalter DJ (2000) Winbugs a Bayesian modelling framework: concepts, structure, and extensibility. Stat Comput 10:325-337

30. Netzer O, Toubia O, Bradlow E, Dahan E, Evgeniou T, Feinberg F, Feit E, Hui S, Johnson J, Liechty J, Orlin J, Rao VR (2008) Beyond conjoint analysis: advances in preference measurement. Mark Lett 19(3/4):337-354
31. Olshavsky RW (1979) Task complexity and contingent processing in decision making: areplication and extension. Organ Behav Human Perform 24(3):300-316

32. Payne JW (1976) Task complexity and contingent processing in decision making: an information search and protocol analysis. Organ Behav Human Perform 16(2):366-387

33. Roberts JH, Lattin JM (1991) Development and testing of a model of consideration set composition. J Mark Res 28(4):429-440

34. Roth KP, Diamantopoulos A (2009) Advancing the country image construct. J Bus Res 62(7):726-740

35. Roth MS, Romeo JB (1992) Matching product category and country image perceptions: a framework for managing country-of-origin effects. J Int Bus Stud 23(3):477-497

36. Samiee $S$ (2010) Advancing the country image construct - a commentary essay. J Bus Res 63(4):442-445

37. Shimp TA, Sharma S (1987) Consumer ethnocentrism: construction and validation of the CETSCALE. J Mark Res 24(280-289)

38. Steenkamp JBEM, Baumgartner H (1998) Assessing measurement invariance in cross-national consumer research. J Consum Res 25(1):78-107

39. Usunier JC, Cestre G (2007) Product ethnicity: revisiting the match between products and countries. J Int Mark 15(3):32-72

40. Verlegh PWJ, Steenkamp JBEM (1999) A review and meta-analysis of country-of-origin research. J Econ Psychol 20(5):521-546 